\title{
Identification of a novel plant-derived attractant for Acromyrmex lobicornis leaf-cutting ants
}

\section{ANDREA M. ALMA ${ }^{1}$, PATRICIA C. FERNANDEZ ${ }^{2,3}$, DAIANA PERRI ${ }^{3}$ and MICAELA BUTELER ${ }^{1}$}

\author{
${ }^{1}$ Laboratorio de Investigaciones en Hormigas, INIBIOMA-UNComahue, Pasaje Gutierrez \\ 1125, CP 8400, San Carlos de Bariloche, Río Negro, Argentina \\ ${ }^{2}$ Consejo Nacional de Investigaciones Científicas y Tecnológicas/CONICET-INTA, Estación \\ Experimental Agropecuaria Delta del Paraná, Río Paraná de la Palmas y Canal Laurentino \\ Comas, 4ta. Sección de Islas CC 14 (2804), Campana Buenos Aires, Argentina \\ ${ }^{3}$ Catedra de Biomoléculas, Facultad de Agronomía, Universidad de Buenos Aires, \\ Av. San Martin 4453, C1417DSE, Buenos Aires, Argentina
}

Manuscript received on October 1, 2018; accepted for publication on March 18, 2018

\begin{abstract}
How to cite: ALMA AM, FERNANDEZ PC, PERRI D AND BUTELER M. 2019. Identification of a novel plantderived attractant for Acromyrmex lobicornis leaf-cutting ants. An Acad Bras Cienc 91: e20181008. DOI 10.1590/00013765201920181008 .
\end{abstract}

\begin{abstract}
Leaf-cutting ants are considered major pests of agriculture and forestry in the Neotropics. Attractive toxic baits are the prevailing method for managing them. Thus, there is great interest in identifying attractants to incorporate into these baits. Moreover, leaf-cutting ants can avoid toxic baits by associating the attractant with the toxin. We evaluated attractiveness of heptyl butyrate, a volatile compound found in fresh apples and plums. We conducted field experiments with ten colonies of Acromyrmex lobicornis. First, we evaluated the behaviour of ants exposed to heptyl butyrate at $1 \%$ by surrounding resources. Then, we compared the attractiveness of heptyl butyrate and orange pulp, the most commonly used attractant. Finally, we evaluated whether heptyl butyrate increases the attractiveness of a carbohydrate resource at varying doses. Heptyl butyrate at $1 \%$ attracted $92 \%$ more ants than the control and that it was as attractive as orange pulp. Heptyl butyrate paired with sucrose at concentrations of 0.001 and $0.1 \%$ was more attractive than sucrose alone, but greater concentrations did not increase sucrose's attractiveness. Therefore, heptyl butyrate could be added to toxic baits to manage $A$. lobicornis as it is as attractive as the most commonly used attractant and can be applied directly to the pellets.
\end{abstract}

Key words: Acromyrmex lobicornis, hepyl butyrate, pest management, toxic baits, attractant.

\section{NOVEL ATRACTANT FOR Acromyrmex lobicornis}

Leaf-cutting ants (LCA) belonging to the genera Atta and Acromyrmex (Order Hymenoptera, Family Formicidae, Tribe Attini) (Hölldobler and Wilson 1990) are recognized as key herbivores and

Correspondence to: Micaela Buteler

E-mail: butelermica@gmail.com

ORCid: https://orcid.org/0000-0002-7252-8424 ecosystem engineers (Farji-Brener and Werenkraut 2015), but also cause large economic losses in numerous crops (Montoya-Lerma et al. 2012). The most commonly used control strategy to manage this pest is the use of toxic baits, which typically consist of a citrus pulp attractant with soybean oil, and sulfluramid or fipronil as the main compounds currently under large-scale use (dos Santos et al. 
2017). However, citrus extracts are not suitable for all species of LCA (Lima et al. 2003), and given their cognitive abilities, LCA can learn to avoid toxic baits by associating the attractant with the toxic compound in the bait (North et al. 1999). In such cases the workers stop harvesting initially accepted resources, a phenomenon known as 'delayed avoidance', which can be prevented by changing the attractant in which the pesticide is applied (Herz et al. 2008, Saverschek et al. 2010). Furthermore, there is great interest in facilitating the encounter of the bait by scout workers by adding attractive odours such as ant pheromones or plant-derived compounds (Carlos et al. 2010, Tatagiba-Araujo et al. 2012). In this study, we evaluated attractiveness of heptyl butyrate, a volatile compound naturally found in fresh apples and plums (Carle et al. 1987, Mattheis et al. 1991). Heptyl butyrate is commercially available as it is used in the food and fragrance industry. It is also used as an attractant for other hymenopteran insects, Vespula spp. wasps (Buteler et al. 2017), making it an interesting candidate with potential as attractant to LCA. Here we investigated its attractiveness alone and coupled with food resources, at different doses, and found it to be as attractive as orange pulp, the most commonly used attractant in toxic baits (dos Santos et al. 2017).

We conducted the study during Austral summer in 2017 in Dina Huapi, Río Negro, Argentina $\left(41^{\circ} 04^{\prime} \mathrm{S}\right.$ and $\left.71^{\circ} 09^{\prime} \mathrm{O}\right)$ in an herbaceous/ shrub steppe vegetation. We carried out three field experiments with ten colonies of the LCA Acromyrmex lobicornis of similar size (mound diameter 50-80 cm and high 20-30 cm). First, we evaluated the behaviour of ants exposed to food sources surrounded by heptyl butyrate. For each nest, two foraging trails with a similar activity were chosen. A bait consisting of 30 oat flakes over a filter paper ( $8 \mathrm{~cm}$ diameter), was placed at approximately $5 \mathrm{~cm}$ from each trail. Treatment consisted of placing the bait over a filter paper treated with 0.1 $\mathrm{ml}$ of a solution of heptyl butyrate at $1 \%$ in ethanol. The control bait was placed on a filter paper treated with $0.1 \mathrm{ml}$ of ethanol. Each nest was exposed to a control and a treated bait. Fifteen minutes after placing the baits, we measured the number of ants walking through each filter paper during 1 minute and analysed it using generalized lineal mixed models (GLMM) with Poisson distribution and nest as random factor in the $\mathrm{R}$ environment (R Development Core Team 2010). We found that heptyl butyrate at $1 \%$ attracted $92 \%$ more ants than control treatment (GLMM, treatment: $\chi^{2}=42.07$, $\mathrm{p}<0.0001$, random effect nest: $\chi^{2}=233.21, \mathrm{p}<$ 0.0001; Fig. 1).

Then, we compared the attractiveness of heptyl butyrate and orange pulp, the most attractive bait so far (Carlos et al. 2010), to determine the potential of heptyl butyrate to be incorporated as attractant in bait matrices for A. lobicornis. We conducted paired choice tests consisting of two filter papers ( 8 $\mathrm{cm}$ diameter) placed at opposite sides of a foraging trail. One of the filter papers was treated with either $2 \mathrm{ml}$ of orange pulp or $0.1 \mathrm{ml}$ of heptyl butyrate at $1 \%$ and the other one was a control with water or ethanol, respectively. Ten minutes after placing the filter papers, we recorded the number of ants walking through them for 1 minute. The number of ants in treated paper minus the number of ants in control one for each treatment was analysed with a t-test. We found a very similar number of ants attracted to heptyl butyrate $1 \%$ as to orange pulp ( $t$ $=0.15$, d.f. $=14.03, \mathrm{p}=0.88$; Fig. 2).

Finally, given that toxic baits are typically comprised of an attractant, and an arrestant or food resource (dos Santos et al. 2017), we evaluated whether heptyl butyrate increases the attractiveness of a carbohydrate resource at varying doses. We used sucrose solution as a carbohydrate resource because the attractiveness of sugars to LCA, as well as the nutritional importance of such compounds for these insects has been well studied (Boaretto et al. 2003). We simultaneously placed filter papers 


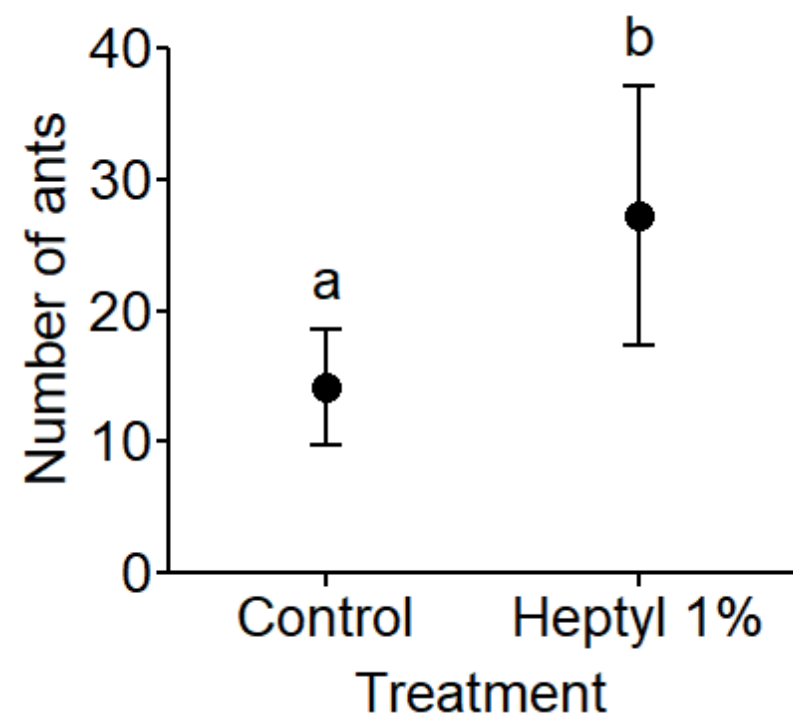

Figure 1 - Number of ants (mean \pm SE) walking during 1 min through filter paper impregnated with ethanol (control) or heptyl butyrate $1 \%$. Different letters indicate significant differences $(\mathrm{p}<0.05, \mathrm{~N}=10)$.

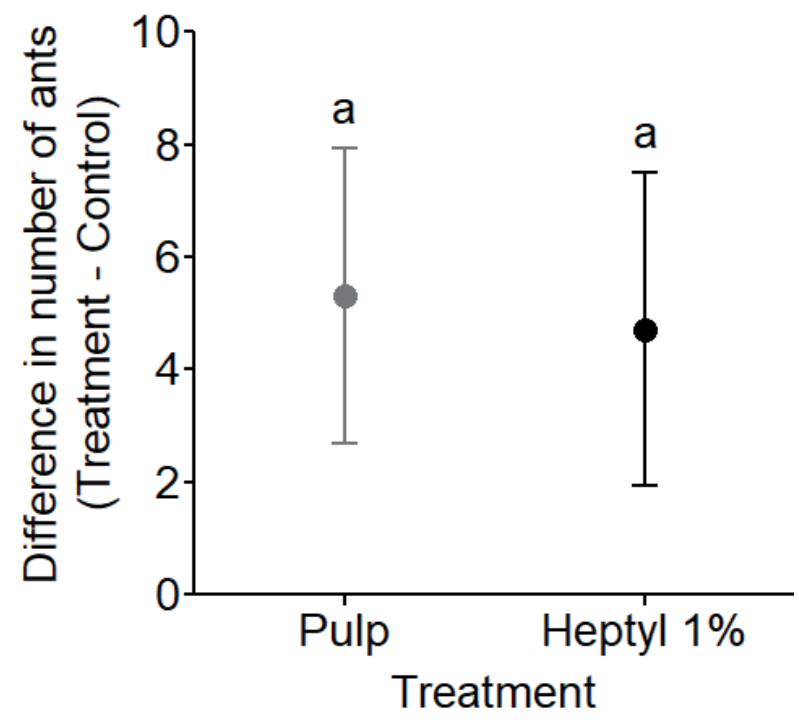

Figure 2 - Difference in number of ants (mean $\pm \mathrm{SE}$ ) in treatment and control filter papers. Treatment filter papers were treated with orange pulp or heptyl butyrate $1 \%$. Similar letters indicate non-significant differences $(\mathrm{p}=0.88, \mathrm{~N}$ pulp $=$ 10 and $\mathrm{N}$ heptyl $=7$ ).

soaked in a saturated sucrose solution in water and impregnated with $0.01,0.1,1$ and $10 \%$ of heptyl butyrate at the sides of a foraging trail. Control filter papers had sucrose solution and solvent. We measured the number of ants arrested at each filter

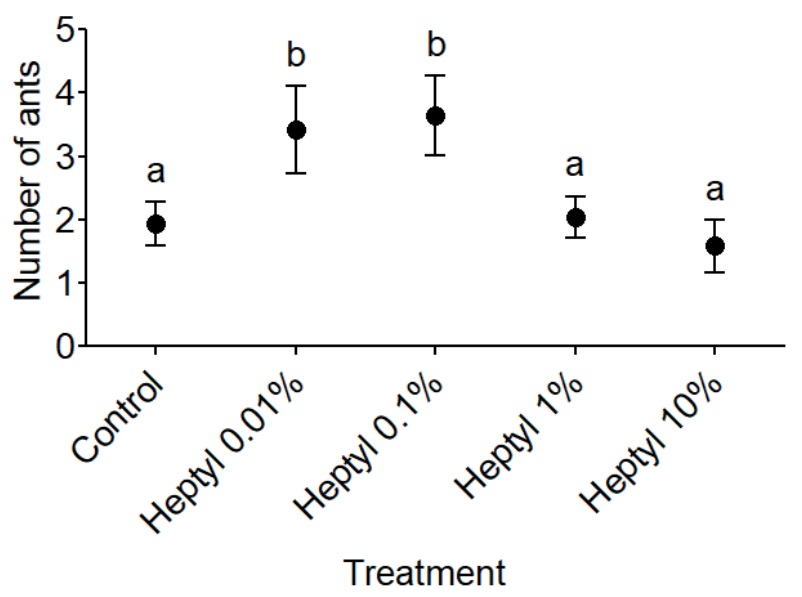

Figure 3 - Number of ants (mean \pm SE) walking through filter paper with sugar and impregnated with ethanol (control) or heptyl butyrate $0.01,0.1,1$ or $10 \%$. Different letters indicate significant differences $(\mathrm{p}<0.05, \mathrm{~N}=7)$.

paper 1, 5, 10, 15 and 30 minutes afterwards. We compared the number of ants at each paper using GLMM with Poisson distribution and time and nest as random factors. Under the conditions of the study, when ants had a choice between the different doses of the attractant simultaneously, we found that sucrose plus heptyl butyrate was more attractive than sucrose alone at concentrations of 0.01 and $0.1 \%$. At higher concentrations heptyl butyrate was as attractive as sucrose alone (GLMM, treatment: $\chi^{2}=38.58, \mathrm{p}<0.0001$, random effect time/nest: $\chi^{2}$ $=142.67, \mathrm{p}<0.0001 ;$ Fig. 3 ).

We report for the first time the attractiveness of a synthetic compound, heptyl butyrate, to the LCA A. lobicornis. The attractiveness depended on the dose, but all doses tested in this study were more attractive or as attractive as the controls when they were paired with a sucrose resource. The success of a toxic bait against LCA depends largely on its attractant (Roces 1990, Lima et al. 2003), and dehydrated citrus pulp may lose attractiveness if ants learn to associate it with the pesticide in the bait. Heptyl butyrate could be added to toxic baits to manage A. lobicornis since it is as attractive as orange pulp and can be applied directly to the pellets. It is also synthetic, commercial, relatively 
inexpensive and, contrary to orange pulp, standard in its composition. This compound could also be used in a management strategy that rotates attractants, in combination to citrus extracts, to avoid delayed avoidance of toxic baits. Future studies should test its attractiveness to other pest species of LCA.

\section{ACKNOWLEDGMENTS}

This project was funded by the Agriculture Ministry, Applied Research Project (PIA 14010) Argentina.

\section{AUTHOR CONTRIBUTIONS}

AMA, PCF, DP and MB conceived ideas. AMA and $\mathrm{MB}$ designed the experiments. AMA, DP and MB carried out field experiments. AMA analyzed data. AMA and MB wrote the manuscript. PF and DP revised the manuscript.

\section{REFERENCES}

BOARETTO MAC, FORTI LC, LOPES JFS, NAGAMOTO NS, ANDRADE APP, MOREIRA AA, VIANA AES AND RAMOS VM. 2003. Response of the grass-cutting ant Atta capiguara Gonçalves, 1944 (Hymenoptera: Formicidae) to sugars and artificial sweeteners. Sci Agric 60: 505-509.

BUTELER M, FERNANDEZ P, STADLER T, WEAVER DK, YOSSEN B AND LOZADA M. 2017. Heptyl butyrate, a putative pheromone involved in social communication of Vespula germanica wasps. Insectes Soc 65: 95-101.

CARLE S, AVERILL A, RULE G, REISSIG W AND ROELOFS W. 1987. Variation in host fruit volatiles attractive to apple maggot fly, Rhagoletis pomonella. J Chem Ecol 13: 795-805.

CARLOS AA, FORTI L, CAMARGO R, VERZA S, BARBOSA L AND LOPES J. 2010. Behavioral response of the leafcutter ant, Atta sexdens rubropilosa (Hymenoptera, Formicidae), to components of citrus pulp. Sociobiology 55: 509-218.
DOS SANTOS C, CAMARGO R DA S, BRUGGER M, FORTI L AND SANTOS LOPES J. 2017. Effect of the presence of brood and fungus on the nest architecture and digging activity of Acromyrmex subterraneus Forel (Hymenoptera, Formicidae). Rev Bras Entomol 61: 80-85.

FARJI-BRENER AG AND WERENKRAUT V. 2015. A meta-analysis of leaf-cutting ant nest effects on soil fertility and plant performance. Ecol Entomol 40: 150-158.

HERZ H, HÖLLDOBLER B AND ROCES F. 2008. Delayed rejection in a leaf-cutting ant after foraging on plants unsuitable for the symbiotic fungus. Behav Ecol 19: $575-582$.

HÖLLDOBLER B AND WILSON EO. 1990. The ants. Berlin, Germany.

LIMA C, DELLA LUCIA T, GUEDES R AND VEIGA C. 2003. Desenvolvimento de iscas granuladas com atraentes alternativos para Atta bisphaerica Forel, (Hymenoptera: Formicidae) e sua aceitação pelas operárias. Neotrop Entomol 32: 497-501.

MATTHEIS JP, BUCHANAN DA AND FELLMAN JK. 1991. Anaerobic metabolism change in apple fruit volatiles after storage in atmospheres inducing. J Agric Food Chem 39: 1602-1605.

MONTOYA-LERMA J, GIRALDO-ECHEVERRI C, ARMBRECHT I, FARJI-BRENER A AND CALLE Z. 2012. Leaf-cutting ants revisited: towards rational management and control. Int J Pest Manag 58: 225-247.

NORTH RD, JACKSON CW AND HOWSE PE. 1999. Communication between the fungus garden and workers of the leaf-cutting ant, Atta sexdens rubropilosa, regarding choice of substrate for the fungus. Physiol Entomol 24: 127-133.

R DEVELOPMENT CORE TEAM. 2010. R: a language and environment for statistical computing.

ROCES F. 1990. Leaf-cutting ant cut fragment sizes in relation to the distance from the nest. Anim Behav 40: 1181-1183.

SAVERSCHEK N, HERZ H, WAGNER M AND ROCES F. 2010. Avoiding plants unsuitable for the symbiotic fungus: learning and long-term memory in leaf-cutting ants. Anim Behav 79: 689-698.

TATAGIBA-ARAUJO G, VIANA-BAILEZ A AND BAILEZ O. 2012. Increasing attractiveness of baits with venom gland extract for Atta sexdens rubropilosa (Forel) (Hymenoptera: Formicidae). Neotrop Entomol 41: 232236. 